\title{
Modeling, Fabrication, and Testing of a Diamond- Machined Germanium Immersion Grating
}

\author{
P.J. Kuzmenko, L.M. Little, P.J. Davis and S.L.Little
}

This paper was presented at SPIE's Conference on IR Space

Telescopes and Instruments, Waikoloa, HI., August 22-28, 2002

September 6, 2002

U.S. Department of Energy

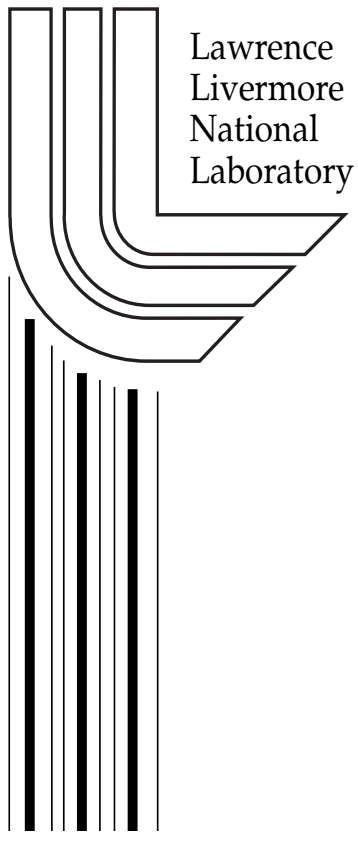




\section{DISCLAIMER}

This document was prepared as an account of work sponsored by an agency of the United States Government. Neither the United States Government nor the University of California nor any of their employees, makes any warranty, express or implied, or assumes any legal liability or responsibility for the accuracy, completeness, or usefulness of any information, apparatus, product, or process disclosed, or represents that its use would not infringe privately owned rights. Reference herein to any specific commercial product, process, or service by trade name, trademark, manufacturer, or otherwise, does not necessarily constitute or imply its endorsement, recommendation, or favoring by the United States Government or the University of California. The views and opinions of authors expressed herein do not necessarily state or reflect those of the United States Government or the University of California, and shall not be used for advertising or product endorsement purposes.

This is a preprint of a paper intended for publication in a journal or proceedings. Since changes may be made before publication, this preprint is made available with the understanding that it will not be cited or reproduced without the permission of the author.

This report has been reproduced directly from the best available copy.

Available electronically at http://www.doc.gov/bridge

Available for a processing fee to U.S. Department of Energy

And its contractors in paper from

U.S. Department of Energy

Office of Scientific and Technical Information

P.O. Box 62

Oak Ridge, TN 37831-0062

Telephone: (865) 576-8401

Facsimile: (865) 576-5728

E-mail: reports@adonis.osti.gov

Available for the sale to the public from

U.S. Department of Commerce

National Technical Information Service

5285 Port Royal Road

Springfield, VA 22161

Telephone: (800) 553-6847

Facsimile: (703) 605-6900

E-mail: orders@ntis.fedworld.gov

Online ordering: http:/ / www.ntis.gov/ordering.htm

\section{OR}

Lawrence Livermore National Laboratory

Technical Information Department's Digital Library

http: / / www.llnl.gov/tid/Library.html 
the immersion design. It also has good transmission from 2 to $14 \mu \mathrm{m}$. Unfortunately, fabrication is a major issue. Efforts by Käufl et al. to chemically etch germanium showed initial promise but the attainable anisotropy (ratio of 2 or 3 ) was much lower than that of silicon. Useful gratings were not achieved. Käufl was later successful in fabricating a hybrid grism by clamping a grating etched on a silicon wafer to a germanium prism. ${ }^{7}$ However, the hybrid approach has significant shortcomings. The gap between the silicon and germanium must be kept below $50 \mathrm{~nm}$ to avoid large reflections at the interface. Thermal mismatch between the two materials makes it a challenge to achieve good clamping over wide temperature ranges. Ebizuka studied oblique ion etching and excimer laser ablation as ways to make immersion gratings in germanium but no results were reported. ${ }^{8}$

At LLNL there has been an ongoing interest in advanced long wave ( 8 to 12 micron) infrared spectrometers. A germanium immersion grating enables a very compact optical design ${ }^{9}$ (see figure 2). Having reservations about the above techniques, we decided to investigate mechanical methods of fabricating germanium gratings. Diamond turning has been used to fabricate high quality germanium optics for a number of years. It remained to be demonstrated that the precision required for a grating was possible with existing machine tools. Section 2 discusses experimental evidence for the feasibility of diamond cut gratings. In section 3, we look at the design and modeling of a specific grating for use in a laboratory spectrometer. Section 4 describes the fabrication techniques. Section 5 presents results of tests on the performance of the machined grating. Section 6 discusses the results and how they compare with other work. Section 7 provides conclusions and recommendations for future work.

\section{FEASIBILITY OF DIAMOND CUT IMMERSION GRATINGS}

Two attempts to diamond cut gratings in infrared transmissive materials were reported at the 1998 SPIE conference in Kona, Hawaii. Rayner reported on diamond ruled $\mathrm{ZnSe}$, but the efficiency was low with severe scattering and the grooves were pitted. ${ }^{10}$ A group from Cornell reported an effort to diamond machine gratings on $\mathrm{ZnS}$ and $\mathrm{ZnSe}$ blanks to determine the feasibility of fabricating a mid-IR grism. ${ }^{11}$ OFC Diamond Turning (now Corning NetOptix) performed the diamond flycutting for the Cornell group on standard one inch diameter, $1 / 4$ inch thick window blanks of polycrystalline $\mathrm{ZnS}$ and on polycrystalline blanks of $\mathrm{ZnSe}$ as well. The gratings had a $3.74^{\circ}$ blaze angle and 91.9 micron periodicity. When contacted in late 1998, the Cornell test rulings had been completed but not tested other than by visual inspection. Under a microscope, pits were observed of about 10 to 20 micron in size. These correspond to the grain size of the polycrystalline material and represent locations where the grains were pulled out during the machining process. The surface density of these defects ranges from 20 to 100 per square millimeter. Assuming that all the light striking a pit is scattered the fraction of incident light scattered by defects is of order $1 \%$.

We tested the Cornell rulings at LLNL to further evaluate their optical performance. Our first test was to determine the roughness and scatter introduced by the machining process. A Tencor P-10 stylus profilometer measured the roughness of the machined surface in pit-free regions. Along a 1/2 millimeter path the average roughness was about $7 \mathrm{~nm}$ for the $\mathrm{ZnS}$ and about $10 \mathrm{~nm}$ for the $\mathrm{ZnSe}$. Scatter is a function of the rms surface roughness $(\sigma)$ and the wavelength of the incident light $(\lambda)$. Total integrated scatter (TIS) is given by ${ }^{12}$

$$
\text { TIS }=(4 \pi \sigma / \lambda)^{2} \text { for } \sigma<<\lambda .
$$

At a wavelength of $10 \mu \mathrm{m}$ with an rms roughness of $10 \mathrm{~nm}$ (rms roughness is somewhat greater than average roughness), the TIS is $0.016 \%$. In immersion, however, the wavelength is reduced by a factor equal to the refractive index. For a germanium $(n=4)$ immersion grating under the same conditions, the TIS would increase to $0.25 \%$. This is an acceptable value, but for operation at much shorter wavelengths a smoother surface may be required.

For a grating to achieve its theoretical resolution, the relative position of each groove must be maintained with extremely high precision. This allows the wavefront of the diffracted waves to match that of the incident wave. If there is greater than $\lambda / 4$ peak to peak $(\lambda / 14 \mathrm{rms})$ error in the wavefront diffracted from the grating, a monochromatic beam will no longer focus to a diffraction-limited spot and the resolution will be degraded. We used a Zygo interferometer to measure the wavefront error in the diffracted beams reflected from the test rulings. The wavefront errors at $633 \mathrm{~nm}$ ranged from $1 / 3$ to $1 / 7$ wave $\mathrm{rms}$ over the $2.5 \mathrm{~cm}$ diameter substrates. Extrapolating this to a wavelength of $2.5 \mu \mathrm{m}$ (which is equivalent to a germanium grating in immersion mode at $10 \mu \mathrm{m}$ wavelength) the wavefront error would range from $\lambda / 12$ to $\lambda / 28 \mathrm{rms}$. This is also acceptable, but would need improvement for use at much shorter wavelengths. 
Our conclusions from the measurements on the Cornell test rulings were that the surface roughness and surface error were adequate. If comparable surface quality were to be achieved in a germanium immersion grating, then it would perform well at 10 microns. So the task appears feasible with existing diamond machining technology. Single crystal germanium is considered to be easier to machine than polycrystalline $\mathrm{ZnS}$ or $\mathrm{ZnSe}$. There is no pitting from grain pull outs. Surface roughness as low as $0.8 \mathrm{~nm}$ rms has been reported for single point diamond turning on single crystal germanium. ${ }^{12}$

\section{DESIGN AND MODELING OF THE GRATING}

Before the design of the immersion grating can begin, one must have a set of optical specifications which flow from the optical design of the system. The optical design in turn flows down from the overall system requirements. A preliminary design is produced by applying geometrical optics and the grating equation. Then the grating efficiency is modeled with electromagnetic codes to optimize and tolerance the design.

For this particular spectrometer, the basic requirements were to cover the atmospheric window from 8.0 to 13.5 microns, to use an off-the-shelf Si:As focal plane array, and to minimize distortion of the slit image in the focal plane while keeping the layout as compact as possible. The spectrometer requires only modest dispersion which can be accomplished with an immersion grating operated at a small blaze angle.

An immersion grating operating in Littrow mode, such as that shown in figure 1, requires a significant out of plane incidence angle to separate the input and output beams. Consequently, severe slit curvature would occur in the focal plane. Instead, we have chosen to operate in non-Littrow mode with an angle of incidence near 45 degrees. This separates the input and output beams by 90 degrees and avoids out of plane incidence angles.

The optical design was done with Zemax (see figure 2). It calls for a germanium immersion grating operating in first order with a groove spacing of $17.3 \mu \mathrm{m}$. The grating is fabricated on a right angle germanium prism whose other angles are $50.8^{\circ}$ and $39.2^{\circ}$. The aperture stop is on the exit face of the prism and measures $7 \mathrm{~mm}$ by $7 \mathrm{~mm}$. Thus, the ruled area on the prism hypotenuse is about $10 \mathrm{~mm}$ by $10 \mathrm{~mm}$.

Zemax indicates the number and location of the transmitted and reflected orders, but does not give any information on the power distribution among the orders. To determine this and to perform optimization and tolerancing on the grating design, an electromagnetic wave calculation is required.

In order to optimize the design prior to fabrication, we modeled the germanium immersion grating using GSolver ${ }$. This is a commercially available code that uses Rigorous Coupled Wave Analysis to solve the vector form of Maxwell's equations in three dimensions. ${ }^{14,}{ }^{15}$ It calculates the diffraction efficiencies for each diffracted order for a user generated grating structure. To verify correct operation, we modeled a grism that had been previously analyzed by Neviere using a different code. ${ }^{16}$ The GSolver model showed good agreement with the published results.

There were several issues to be examined using the model. Of particular interest was the selection of the blaze angle for best overall efficiency. We also wanted to compare the performance of a metal-coated grating with an uncoated grating relying on total internal reflection. Calculations on reflection gratings have showed that efficiency varies with the angle at the base of the groove. ${ }^{17}$ It would be interesting to see if this effect occurs in an immersed grating. Finally, there was some concern over the effect of having a rounded corner in the groove instead of a perfectly sharp one. It is not possible to fabricate a zero radius of curvature point in the diamond tool. Tool wear during the cutting process could also degrade the sharpness of the corner.

The first optimization involves the blaze of the grating. Scalar theory tells us that the blaze wavelength is diffracted at the same angle as a specular reflection. Since this grating is intended for use over a range of $7.5 \mu \mathrm{m}$ to $13.5 \mu \mathrm{m}$, the blaze wavelength was initially chosen to be the center wavelength of $10.5 \mu \mathrm{m}$. This gives a blaze angle of $6.5^{\circ}$. As seen in Figure 3, the peak efficiency is $75 \%$. However, the efficiency drops off more quickly at lower wavelengths than for wavelengths above the center, such that this design produced undesirably low efficiencies at the low-wavelength end of the range. By changing the blaze wavelength to $9.5 \mu \mathrm{m}$ and the blaze angle to $6.0^{\circ}$, the peak efficiency is increased to 
$78 \%$, and the efficiencies at the low and high ends of the range are above $50 \%$. Notice that the lower blaze angles give higher peak diffraction efficiencies due to less shadowing of the grooves.

The next design decision is whether to coat the grooves with gold to enhance their reflectivity and improve the overall efficiency of the grating. A cursory analysis would seem to indicate that angle of incidence on the grating facets $\left(\sim 45^{\circ}\right)$ is well above the critical angle for germanium $\left(14.5^{\circ}\right)$ and therefore all radiation experiences total internal reflection (TIR). While true for waves at a planar interface, this is not true for a grating. Four transmitted orders are allowed by Maxwell's equations. While these orders have low efficiency, they still diminish the efficiency of the desired reflected order, and a reflective coating would eliminate them. On the other hand, gold is not a perfect reflector. There is absorption due to ohmic losses. Also, the reflectivity at an interface depends on the refractive index mismatch. The mismatch is less between $\mathrm{Au}$ and $\mathrm{Ge}$ than between $\mathrm{Au}$ and air. So the immersed reflectivity of gold is several percent less than its reflectivity in air.

The results of the comparison are shown in Figure 4. The gold coating actually decreases the efficiency for wavelengths below about $8.1 \mu \mathrm{m}$ by as much as $0.5 \%$, but above this wavelength the efficiency increases, with an improvement around $5 \%$ at $13.5 \mu \mathrm{m}$. This is not a dramatic improvement, but it may make coating a worthwhile effort under some circumstances.

There are other considerations that come into play in making a decision on coating. The differential expansion between $\mathrm{Au}$ and $\mathrm{Ge}$ is 1.0E-5 per degree $\mathrm{C}$. Induced stress may cause bending and optical distortion as the grating is cooled from the deposition temperature down to cryogenic operating temperatures. The TIR option is not without concerns. The reflectivity is very sensitive to small amounts of surface contamination. Strict cleaning and handling procedures must be observed. Care must be taken to avoid cryopumping vacuum contaminants onto the grating surface.

Polarization dependent effects are possible when there is reflection at non-normal incidence from dielectrics. This is the case for the unmetallized grating. The model predicts little difference in reflectivity $(<3 \%)$ between the TE and TM waves. Phase shifts between the TE and TM waves may alter the polarization state but the model does not provide information on this parameter.

The model was rerun for a range of groove angles from $85^{\circ}$ to $110^{\circ}$ (previous cases were all run at $90^{\circ}$ ). Very little change in efficiency was noted.

The third portion of the analysis involved the effect of a non-zero radius of curvature of the diamond cutting tool. It is difficult to make a tool with less than $0.5 \mu \mathrm{m}$ radius of curvature, and even if a smaller radius were possible, it would degrade with wear. The model was used to determine the maximum reasonable radius of curvature for use in cutting a grating in germanium. The grating profile in Figure 5 compares an ideal grating (dashed lines) and a grating cut with a tool having some rounding at the tip. The modeled grating has a period of $17.2 \mu \mathrm{m}$ and a depth of $1.8 \mu \mathrm{m}$.

The modeled results are shown in Figure 6. This plot compares the diffraction efficiency for various tool radii. As the radius of curvature $(\mathrm{Rc})$ increases, the wavelength of peak efficiency is decreased. The efficiency actually increases uniformly for curvatures below $1.5 \mu \mathrm{m}$. At $2 \mu \mathrm{m}$, the high-wavelength end of the range shows decreased efficiency, although the low wavelengths still show increasing efficiency. Not until the curvature is increased above $2 \mu \mathrm{m}$ does the efficiency uniformly decrease. This gives significant leeway in tool design.

\section{FABRICATION}

Once the optical design of the immersion grating was finalized and satisfactory performance was predicted by the modeling, attention turned to fabricating the device. We located a vendor with Precitech Nanoform (mod 2400) diamond turning lathes who agreed to flycut test rulings in single crystal germanium. The initial attempt at a feed rate of $75 \mathrm{~mm}$ per minute and a spindle speed of $1200 \mathrm{rpm}$ gave disappointing surface quality with visible brittle fracture surface damage. Reducing the feed rate to $7.5 \mathrm{~mm}$ per minute, which is closer to OFC's recommendation of $3 \mathrm{~mm}$ per minute, produced grooves that were damage free under a microscope. This feed rate results in long machining cycle times (e.g. 11 hours for a $10 \mathrm{~mm}$ by $10 \mathrm{~mm}$ grating with a $20 \mu \mathrm{m}$ period). This is not unprecedented, as conventional ruling engines 
have taken weeks to complete large gratings. However, care must be taken to ensure mechanical stability and tight environmental (temperature) control over the duration of the cutting.

We performed some measurements to evaluate the test rulings. Regions of the cut surface were measured with an optical profilometer. The best areas were around $20 \mathrm{~nm}$ in roughness, which is not bad. However, interferometric examination showed large errors in the diffracted wavefront over small distances, too large for the Zygo to track. We believe this was caused by a lack of environmental control in and around the machine. The commercial lathe's work zone is contained within an enclosure but there is no provision to regulate its temperature. Also the germanium was cut dry, without any cutting fluid. Cutting fluid (light mineral oil) delivered to the workpiece can serve as a temperature stabilizing bath and readily absorb any heat generated in the cutting process. At this point we began to consider using the precision machining resources at LLNL.

There is a long history of precision engineering at LLNL developed in support of various weapons programs but often made available to a wider community. The Large Optics Diamond Turning Machine (LODTM), for example, was used to fabricate infrared secondary mirrors for the Keck telescope. Work has included both research into ultraprecision machining and also the construction of one of a kind machine tools. Other machine tools dedicated to research on ultraprecision diamond turning include the Precision Engineering Research Lathe or PERL, which was constructed in 1983. It soon became committed to parts production and a nearly identical machine, designated the PERL-II, was constructed a year later to carry on the research. ${ }^{18}$ Full numerical control was implemented in 1985 and the design earned an IR 100 award a few years later.

Each PERL machine is constructed on a granite base of dimensions $1.2 \times 1.2 \times 0.35$ meter, which is supported on pneumatic isolators. Two independent, liquid hydrostatic slides are mounted to the base, one to translate the spindle and drive motor and the other to translate the cutting tool. This results in a very stiff, well-damped system with a small structural loop which gives high precision. The slide positions are measured by laser interferometers and controlled by computer. Straightness of motion for the total range of travel $(100 \mathrm{~mm})$ of each slide is $100 \mathrm{~nm}$. Angular motion is less than 1 arc second.

Careful consideration of thermal issues is a key to long term, mechanical stability. The facility in which the PERL-II resides is temperature controlled to $\pm 1^{\circ} \mathrm{C}$. The machine itself is completely enclosed with recirculating, down-draft airflow controlled to $0.01{ }^{\circ} \mathrm{C}$. Water cooling is supplied to the major heat source, the spindle motor, and $0.01^{\circ} \mathrm{C}$ stability is achieved. Finally the temperature of the cutting fluid that floods the workpiece is also controlled. With these measures, the long term stability and repeatability of the PERL-II has been measured to be $<100 \mathrm{~nm}$.

After discussions with the Precision Systems and Manufacturing Group at LLNL, the PERL-II appeared to offer the best chance for successful fabrication of the germanium immersion grating. We specified and procured the germanium blanks and associated fixturing. Single-crystal diamond cutting tools were obtained from Chardon Tool.

Before cutting the germanium, the performance of the PERL-II machine needed to be verified. The first test was to configure the PERL as a conventional lathe and face cut a flat surface on the end of a rod of OFHC copper. Copper is used because diamond cuts it well with minimal tool wear. The surface is then examined interferometrically to look for any errors or irregularities in the cut. On the first attempt, periodic steps of 75 to $100 \mathrm{~nm}$ in height were observed. The cause was eventually traced to varnish deposits from the oil in the hydrostatic slides producing excess drag and stiction. After draining the oil, flushing the slides with solvent and refilling the system with fresh oil, the PERL was performing at its original specifications.

The next test was to cut a test grating in copper identical to the one planned for germanium. Since the copper is relatively soft and ductile, there are no limitations placed by the material. The surface finish and accuracy will be as good as can be achieved with the machine. A somewhat unconventional tool configuration was used. Typically, the workpiece is fastened to the spindle rotor and rotated while a fixed tool is translated in from the side to perform the cutting. However, to cut straight grooves, it was necessary to mount the tool to the spindle rotor. The workpiece is fastened to the transverse slide and translated horizontally under the rotating tool to mill each groove (see figure 7). The grating blaze angle is determined by the angle scaifed into the diamond tool. 
The copper was cut at a much faster feed rate than would be used with the germanium, about $38 \mathrm{~mm}$ per minute. The spindle rotated at $500 \mathrm{rpm}$. The groove roughness was measured by optical profilometer to be $4.3 \mathrm{~nm} \mathrm{rms}$. The diffracted wavefront error measured on a Zygo interferometer was $\lambda / 23 \mathrm{rms}$. These numbers were both very encouraging.

We procured prism blanks of single crystal optical grade n-type germanium from Eagle-Picher Inc. The hypotenuse (grating surface) was specified to be a (110) crystal plane. The orientation of the surface within the (110) plane was further specified so that the direction of cut would be $45^{\circ}$ from major crystal axes (e.g. the (100)). ${ }^{19}$ Doing this reduces the tendency to fracture while cutting and allows the greatest depth of cut in the ductile mode. ${ }^{20}$

Blanks were saw cut and ground to shape by the vendor, holding dimensional tolerances of \pm 0.003 inches, prism angle tolerance of $\pm 0.25^{\circ}$, and crystal orientation of $\pm 3^{\circ}$. These saw cutting and grinding processes leave subsurface damage in the germanium to a depth of about $50 \mu \mathrm{m}$. They can also embed abrasive particles in the surface. It is very important that any such abrasive be removed, otherwise the diamond tool will be damaged and the cut likely ruined. A chemical etch is a good way to remove damaged surface layers and embedded particles. We used a mixture of $\mathrm{HNO}_{3}, \mathrm{CH}_{3} \mathrm{COOH}$, and $\mathrm{HF}$ in the ratio of $18: 8: 5$ by volume $\mathrm{e}^{21}$ at $24^{\circ} \mathrm{C}$. Immersing the prisms in this solution with gentle agitation for 5 minutes removes about $65 \mu \mathrm{m}$ of material. This particular etchant is a polishing etchant. The ground faces became shiny and the surface roughness as measured by a stylus profilometer was reduced from $0.7 \mu \mathrm{m}$ to $0.2 \mu \mathrm{m}$. Diamond cutting can then be done on a pristine surface free of microcracks and crystal flaws. After etching, the entrance and exit faces of the prism were hand polished to a flatness of better than $\lambda / 50 \mathrm{rms}$ at $633 \mathrm{~nm}$.

The germanium grating blank is fixtured in a holder made from tool steel, supported at three points and secured with a thermoplastic material. The holder is fastened to the translation stage and carefully leveled. Better leveling means that the depth of cut can be less while still fully forming the grooves. Before beginning the cutting, the spindle system is run at speed for about two hours so that thermal equilibrium can be achieved. Once all temperatures are stable, numerical control is activated and the cutting begins. A low volume flow of light mineral oil is directed across the workpiece to provide for heat and chip removal. It takes roughly 24 hours to cut a $10 \mathrm{~mm}$ by $10 \mathrm{~mm}$ grating with a $21 \mu \mathrm{m}$ pitch.

After the grating is cut, preliminary tests are performed with the germanium still in the fixture. These include visual and microscopic examination, measurements of surface roughness with an optical profilometer and an atomic force microscope (AFM), and a check of the diffracted wavefront error with an interferometer. The results of these measurements are reported in the next section.

If the results are satisfactory, the thermoplastic is heated to soften it and the germanium is carefully removed. After cleaning, the prisms are sent out for anti-reflection coatings on the entrance and exit faces. Further tests are done with a $\mathrm{CO}_{2}$ laser to determine grating efficiency in immersion mode and to look for grating ghosts. This latter test may also be performed in reflection mode.

\section{TESTING}

Due to time constraints, only the preliminary tests could be performed and are reported here. The first try at machining germanium gave the extremely good surface figure $(\lambda / 100 \mathrm{rms}$ at $633 \mathrm{~nm})$ shown in figure 8 . The grating performance would surely be diffraction-limited. The surface roughness as measured by an optical profilometer along a $60 \mu \mathrm{m}$ path was $4.3 \mathrm{~nm}$ rms. However, due to irregularities in the surface of the blank, the grooves were not cut to full depth in a 2 $\mathrm{mm}$ wide region around the periphery of the grating.

The grating was recut more deeply. Unfortunately, a glitch in the cutting process for reasons still being investigated produced a $100 \mathrm{~nm}$ vertical step in groove position in the middle of the grating. Even with this step the rms surface figure at $633 \mathrm{~nm}$ was still only $\lambda / 20$ and the grating would again be diffraction limited. An atomic force microscope was used to examine the groove profile of this second cut. Figure 9 shows the excellent three-dimensional profile. Statistics done on a $5 \mu \mathrm{m}$ by $5 \mu \mathrm{m}$ area of a groove facet gave an rms roughness of $1.1 \mathrm{~nm}$. By applying equation 1 the total integrated scatter in immersion is calculated to be $0.003 \%$ at $10 \mu \mathrm{m}$ and $0.08 \%$ at $2 \mu \mathrm{m}$. 


\section{DISCUSSION}

Ebizuka has recently published an alternative approach to fabricating germanium immersion gratings based on ultraprecision grinding. ${ }^{22,}{ }^{23}$ Working on a large grating with a $28 \mathrm{~mm}$ clear aperture and a $68.75^{\circ}$ blaze, he obtained 0.38 wave $\mathrm{p}-\mathrm{v}$ wavefront error at $633 \mathrm{~nm}$. The surface roughnesses parallel and perpendicular to the grooves were 21 and 45 $\mathrm{nm}$ rms, respectively. The feed rate is very fast, on the order of $600 \mathrm{~mm}$ per minute, with 0.5 to $2.0 \mu \mathrm{m}$ removed per cut. This technique is better suited for deep, coarse grooves than for the shallow, fine grooves we require. Ebizuka reported a minimum groove radius of about $12 \mu \mathrm{m}$. An update on this work was presented at the 2002 SPIE Astronomical Telescopes and Instrumentation meeting. ${ }^{24}$

\section{CONCLUSIONS}

The germanium immersion gratings fabricated here are of very high quality in the two aspects measured, wavefront aberration and surface roughness (scatter). They would perform well not only in the $8 \mu \mathrm{m}$ to $13.5 \mu \mathrm{m}$ design range, but also down to the $2 \mu \mathrm{m}$ cutoff of germanium, albeit operating in higher order.

The diamond cutting process is rather slow, requiring nearly 24 hours to cut the $10 \mathrm{~mm} \times 10 \mathrm{~mm}$ gratings discussed here. To fabricate gratings suitable for some of the SOFIA first-light instruments (FLITECAM and FORCAST have 25 to 30 $\mathrm{mm}$ pupils) would take nearly a week but would still be possible. For much larger gratings a grinding process similar to that mentioned above may be more appropriate.

Future work will include complete characterization of existing machined gratings especially with regard to efficiency and ghosting. We will also investigate the possibility of cutting coarser, deeper grooves by this technique and look at options for reducing the machining time.

\section{ACKNOWLEDGMENTS}

Many people contributed to the success of this project. Steve Rinehart of Cornell arranged the loan of their $\mathrm{ZnS}$ and ZnSe test rulings that demonstrated feasibility. Izzy Lewis and Charlie Bennett produced the optical design that showed the benefit of a germanium immersion grating. Jackie Crawford etched the germanium blanks and Peter Thelin polished the entrance and exit faces. Charlie Cass restored the performance of the PERL-II to original specifications. Marcia Kellam took interferometric measurements and Jeff Carr produced the AFM data of the grating surface.

This work was performed under the auspices of the U.S. Department of Energy by the University of California, Lawrence Livermore National Laboratory under Contract No. W-7405-Eng-48.

\section{REFERENCES}

1. E. Hulthen and H. Neuhaus, "Diffraction Gratings in Immersion," Nature 173, pp. 442-443, 1954.

2. G. Wiedemann and D.E. Jennings, "Immersion grating for infrared astronomy," Applied Optics 32, pp. 1176-1178, 1993.

3. U.U. Graf, D. T. Jaffe, E. J. Kim, J. H. Lacy, H. Ling, J. T. Moore and G. Rebeiz, "Fabrication and evaluation of an etched infrared diffraction grating," Applied Optics 33 pp. 96-102, 1994.

4. P. J. Kuzmenko, D. R. Ciarlo and C. G. Stevens, "Fabrication and testing of a silicon immersion grating for infrared spectroscopy," in Optical Spectroscopic Techniques and Instrumentation for Atmospheric and Space Research, Proceedings of SPIE vol. 2266, pp. 566-577, 1994.

5. J. Ge, D. McDavitt, J. Bernecker, S. Miller, D. Ciarlo and P. Kuzmenko, "Development of Silicon Grisms and Immersion Gratings for High Resolution Infrared Spectroscopy," in Optical Spectroscopic Techniques and Instrumentation for Atmospheric and Space Research IV, Proceedings of SPIE vol. 4485, pp.393-404, 2001.

6. F.A. Johnson, "Lattice Absorption Bands in Silicon," Proceedings of the Physical Society of London 73, pp.265$272,1959$.

7. H.U. Käufl, K. Kühl and S. Vogel, "Grisms from Germanium/Silicon for Astronomical Instruments," in Infrared Astronomical Instrumentation, Albert M. Fowler, Editor, Proceedings of SPIE Vol. 3354, pp.151-158 (1998). 
8. N. Ebizuka, M. Iye, T. Sasaki and M. Wakaki, "Development of high dispersion grisms and immersion gratings for spectrographs of Subaru Telescope," in Optical Astronomical Instrumentation, Sandro D'Odorico, Editor, Proceedings of SPIE Vol. 3355, pp.409-416 (1998).

9. C. Bennett, I. Lewis, S. Lerner, private communication (2001).

10. J.T. Rayner, "Evaluation of a solid KRS-5 grism for infrared astronomy," in Infrared Astronomical Instrumentation, Albert M. Fowler, Editor, Proceedings of SPIE Vol. 3354, pp.289-294 (1998).

11. J.D. Smith, S.A. Rinehart, J.R.Houck, J.E. Van Cleve, J.C. Wilson, M. Colonno, J. Schoenwald, B. Pirger and C. Blacken, "SCORE 1+: Enhancing a Unique Mid-Infrared Spectrograph," in Infrared Astronomical Instrumentation, Albert M. Fowler, Editor, Proceedings of SPIE Vol. 3354, pp.798-809 (1998).

12. J.M. Bennett and L. Mattsson, Introduction to Surface Roughness and Scattering, (Optical Society of America, Washington, D.C., 1989) pp.51-52.

13. P.N. Blake and R.O. Scattergood, "Ductile-Regime Machining of Silicon and Germanium," Journal of the American Ceramic Society 73, pp.949-957, 1990.

14. Gsolver is a product of the Grating Solver Development Company, P.O. Box 353, Allen TX 75013. More information is available on their website at www.gsolver.com

15. D. Prather, "Software reviews: Optical gratings can be analyzed with clicks," IEEE Spectrum 35, pp. 91-92, June 1998.

16. M. Neviere, "Electromagnetic study of transmission gratings," Applied Optics 30, No. 31, pp. 4540-4547, 1 November 1991

17. G.W. Stroke, "Diffraction Gratings," in Handbuch der Physik, vol. 29, editor S. Flugge, (Springer-Verlag, Berlin, 1967) p.580-583

18. R.R. Donaldson and D.C. Thompson, "Design and Performance of a Small Precision CNC Turning Machine," CIRP $36^{\text {th }}$ General Assembly, Haifa Israel, August 1986.

19. S. Gouquan, C. Yongxiang, Y. Junyi, M. Wensheng, H. Rongjiu and H. Wei, "Investigation on the fan-shaped distribution of surface roughness on diamond-turned single crystal germanium," Progress in Natural Science 6, pp.181-188, 1996.

20. T. Nakasuji, S. Kodera, S. Hara, H. Matsunaga, N. Ikawa and S.Shimada, "Diamond Turning of Brittle Materials for Optical Components," Annals of the CIRP 39, pp. 89-92, 1990.

21. S.K. Ghandhi and J.E. Ayers, "Chemical Etching of Germanium," Journal of the Electrochemical Society 135, pp. 2053-2054, 1988.

22. H. Ohmori, N. Ebizuka, S. Morita and Y. Yamagata, "Ultraprecision Micro-Grinding of Germanium Immersion Grating Element for Mid-Infrared Super Dispersion Spectrograph," Annals of the CIRP 50, pp. 221-222, 2001.

23. N. Ebizuka, H. Kobayashi, Y. Hirahara, M. Wakaki, K. Kwawguchi, T. Sasaki and M. Iye, "Development of Grisms \& Immersion Gratings for the Spectrographs of the Subaru Telescope," in Imaging the Universe in three dimensions:astrophysics with advanced multi-wavelength imaging devices, W. van Breugel and J. Bland-Hawthorn, editors, ASP Conference Series Vol. 195, pp.564-567 (2000).

24. N. Ebizuka, S. Morita, T. Shimizu, Y. Yamagata, H. Omori, M. Wakaki, H. Kobayashi, H. Tokoro and Y. Hirahara, "Development of Immersion Grating for Mid-Infrared High Dispersion Spectrograph for the 8.2m Subaru Telescope," in Specialized Optical Developments in Astronomy, Proceedings of SPIE Vol. 4842 (2002). 


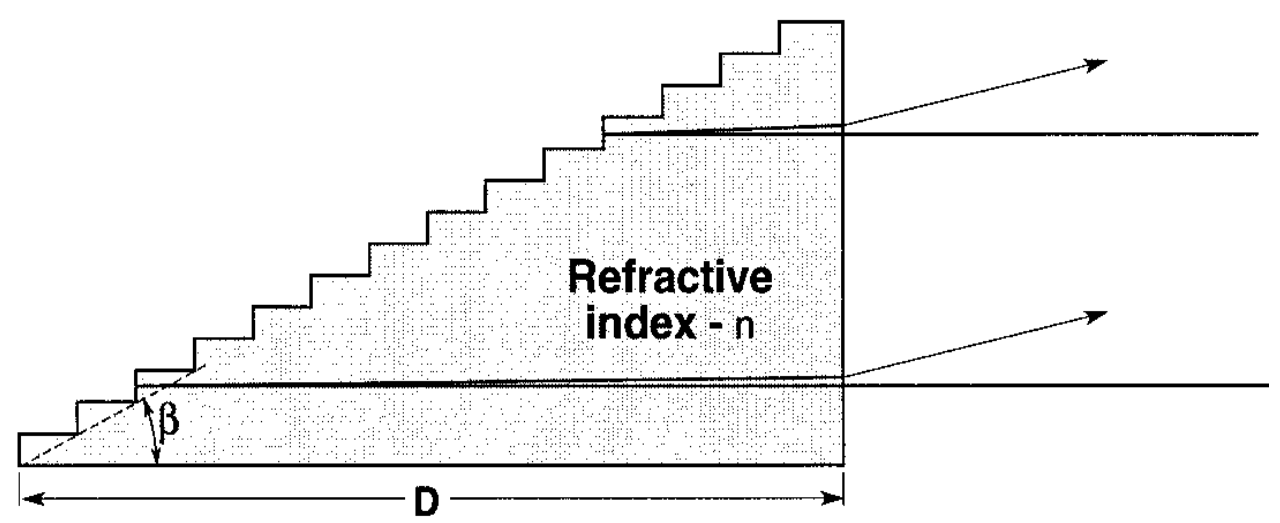

$$
\begin{aligned}
\text { Resolving power }(R) \frac{\lambda}{\Delta \lambda} & =\frac{\mathrm{nD}}{1 / 2 \lambda} \\
\text { Linear dispersion } & =\frac{\mathrm{nf}}{(1 / 2 \lambda) \tan \beta}
\end{aligned}
$$

Figure 1 An immersion grating is one fabricated on a transparent solid with incident and diffracted beams totally within that solid. The dispersion and spectral resolution are improved relative to a grating in air by a factor equal to the refractive index of the solid.

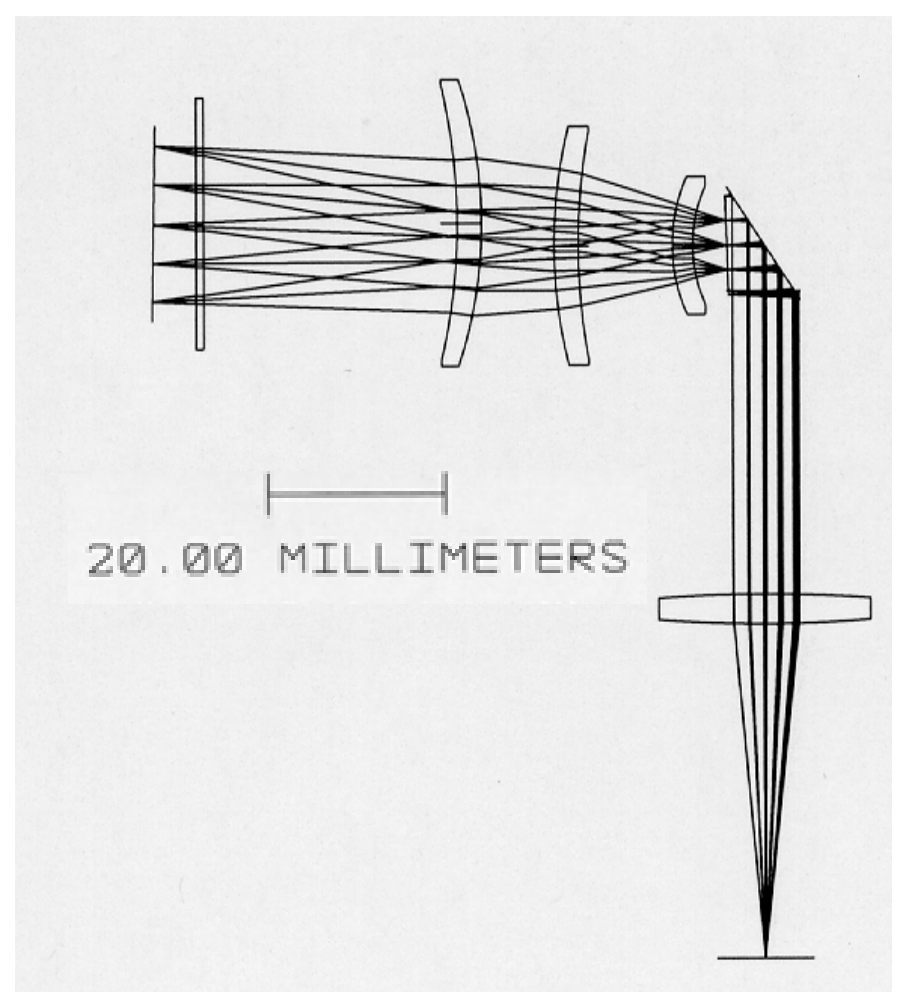

Figure 2 Zemax layout of a long wave infrared immersion grating spectrometer. The grating is machined on the hypotenuse of a triangular prism. The incident beam enters one face of the prism (angle of incidence is 51 degrees) and the diffracted beam exits the other face. 


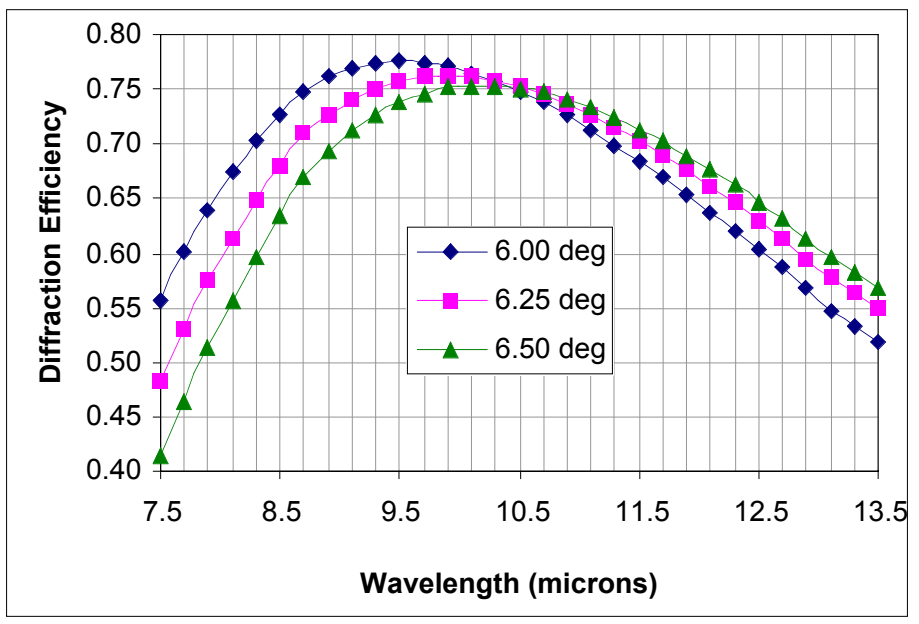

Figure 3 A comparison of modeled diffraction efficiency vs. wavelength for several blaze angles. This calculation is made for a germanium immersion grating with a 17.3 micron groove spacing and an angle of incidence of 50.8 degrees. The grooves are uncoated and the entrance and exit faces have ideal AR coats.

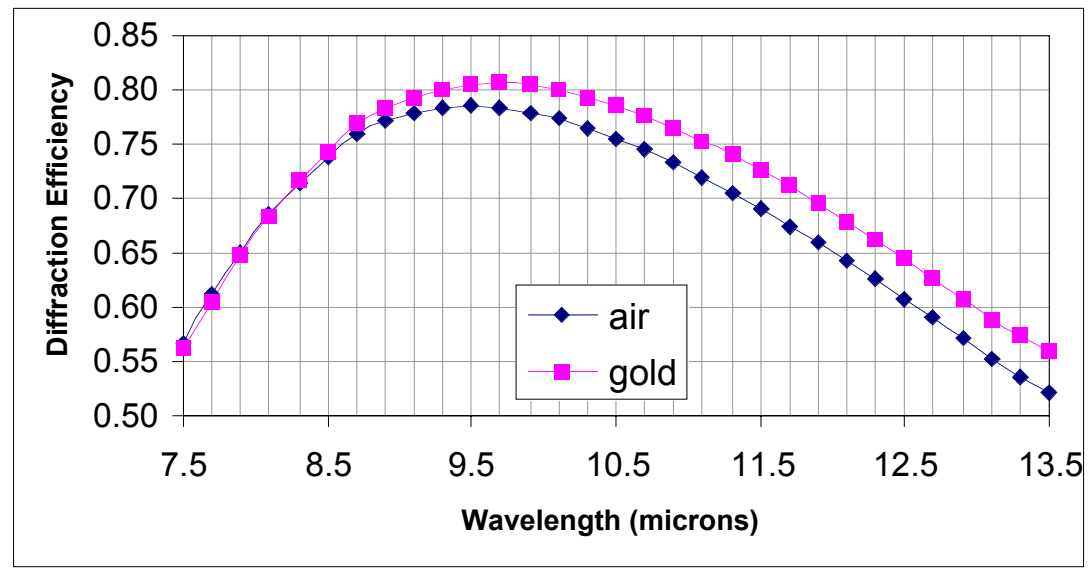

Figure 4 A comparison of the modeled diffraction efficiency vs. wavelength for the cases of uncoated (air) and gold-coated (gold) grooves. This is for the grating in figure 3 with the 6.0 degree blaze.

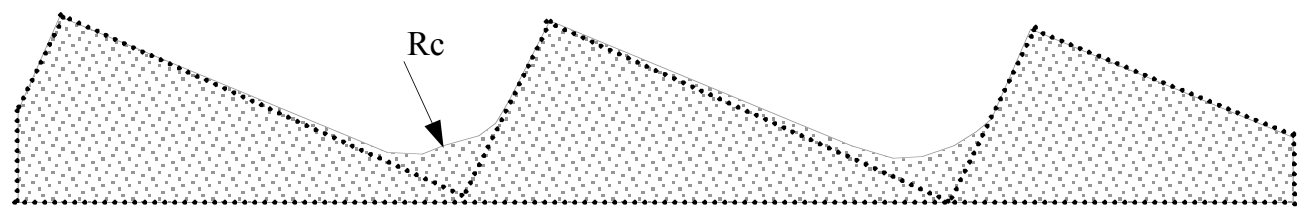

Figure 5 Comparison of ideal grating (dashed lines) to a grating cut with a stylus having finite curvature at the tip. The blaze angle is exaggerated to emphasize the curvature. Rc is the radius of curvature. 


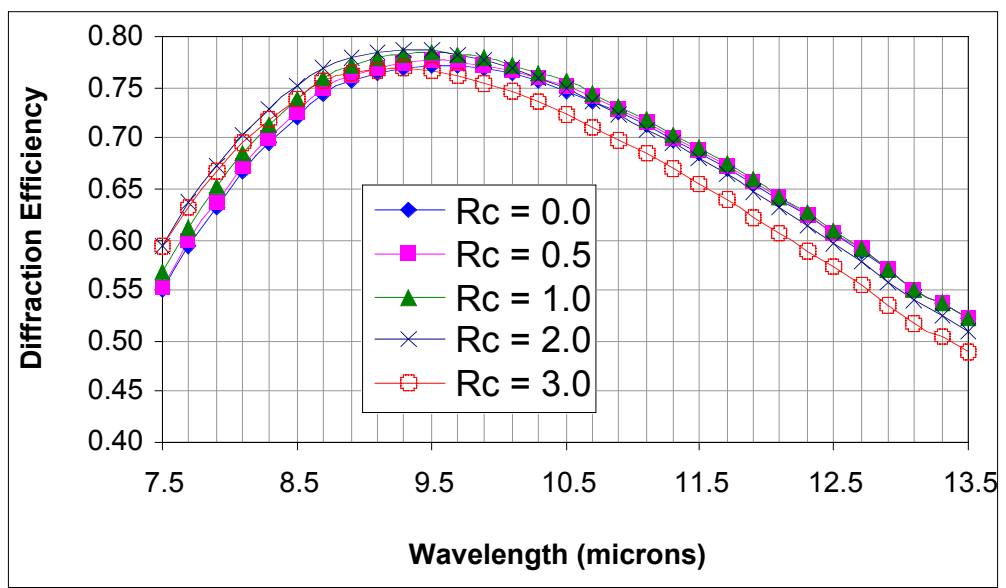

Figure 6 Diffraction efficiency vs. wavelength is plotted for several values of the radius of curvature of the cutting tool. Rc is the radius of curvature in $\mu \mathrm{m}$.

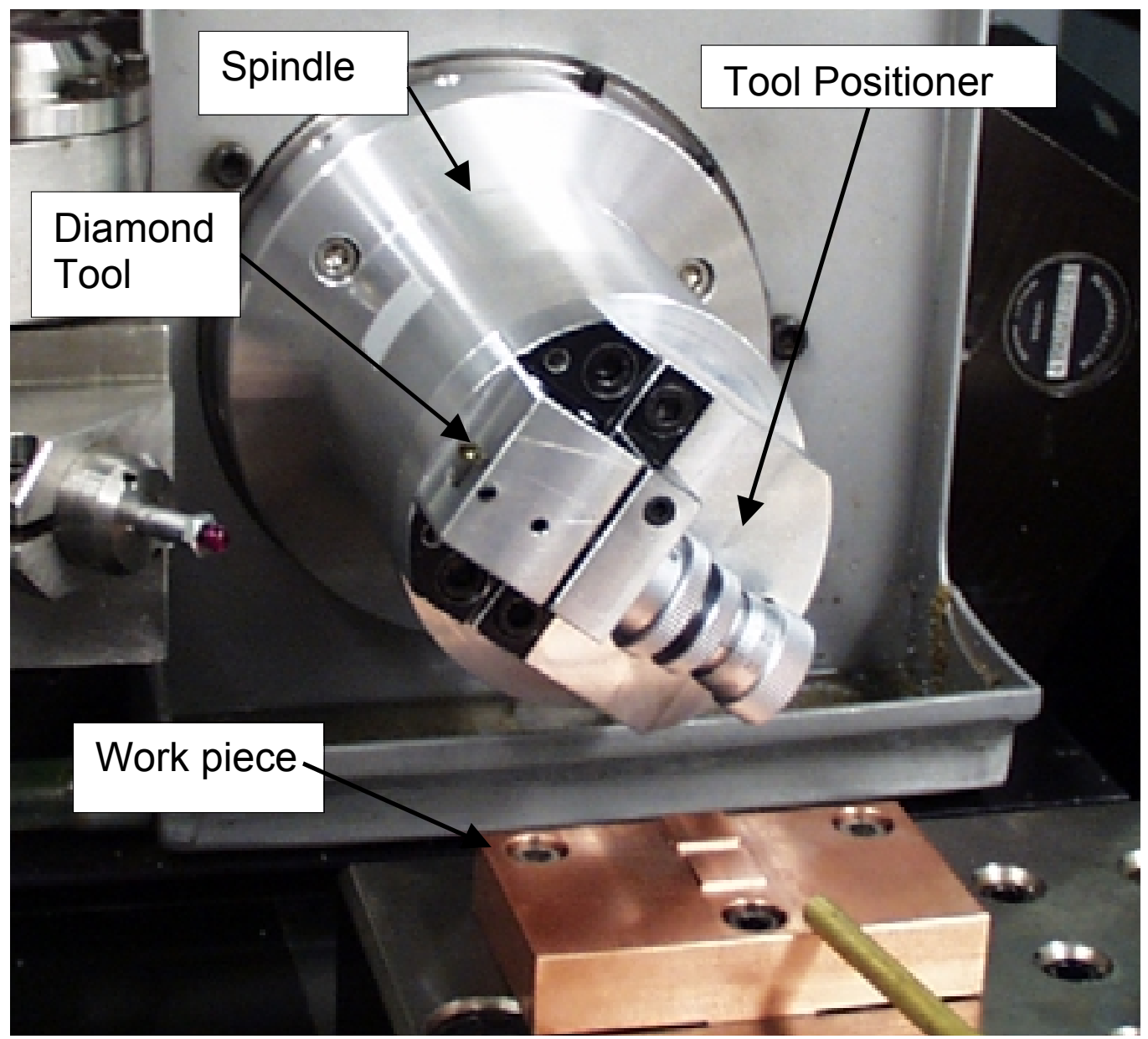

Figure 7 This is the setup of the PERL-II machine for cutting a test grating in copper. The spindle translates axially and the copper work piece translates transversely during the cutting process. 


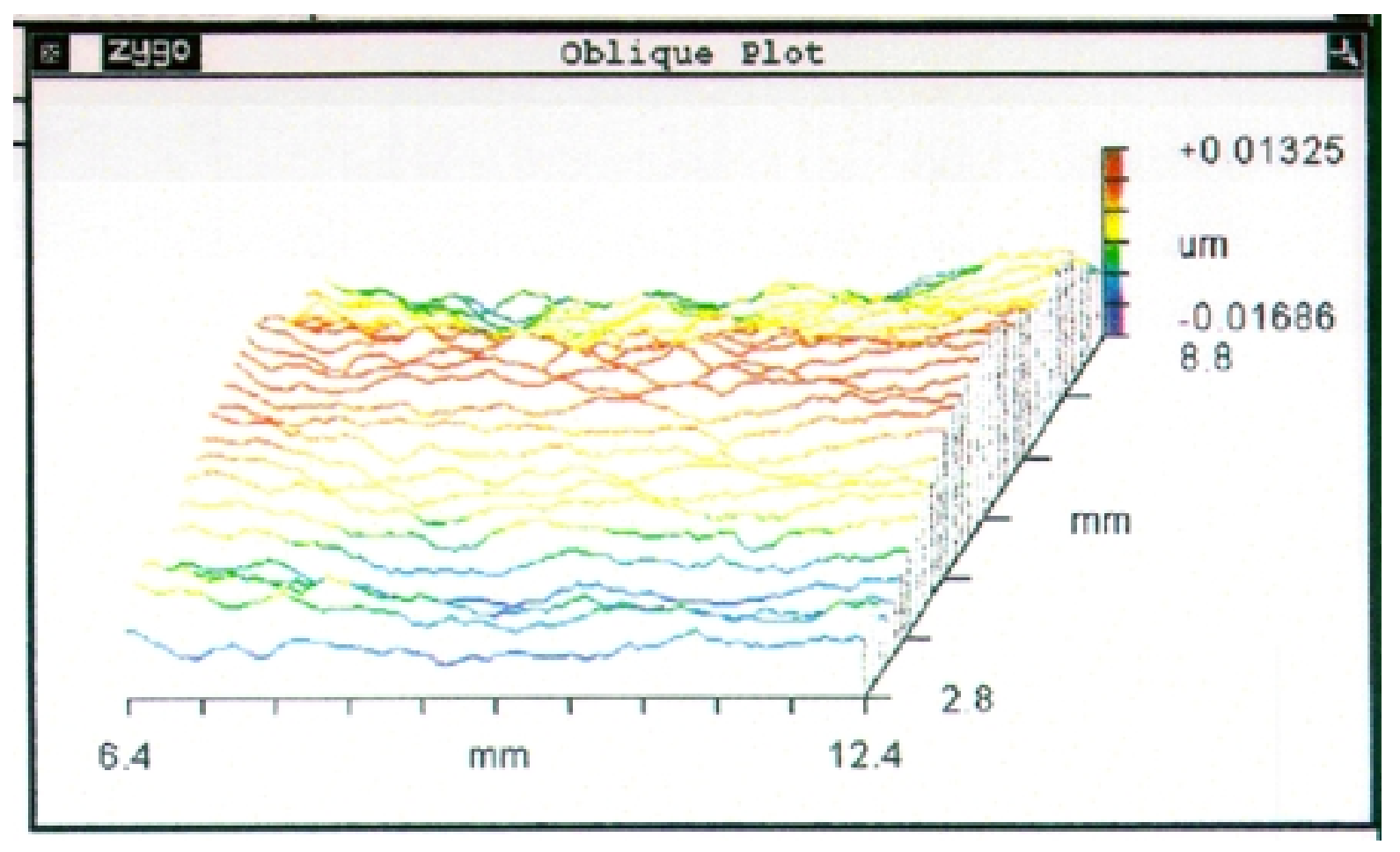

Figure 8 This is an oblique plot of the surface figure of the machined germanium grating facets. The RMS wavefront error at $633 \mathrm{~nm}$ is 0.048 wave peak to valley and 0.010 wave rms.

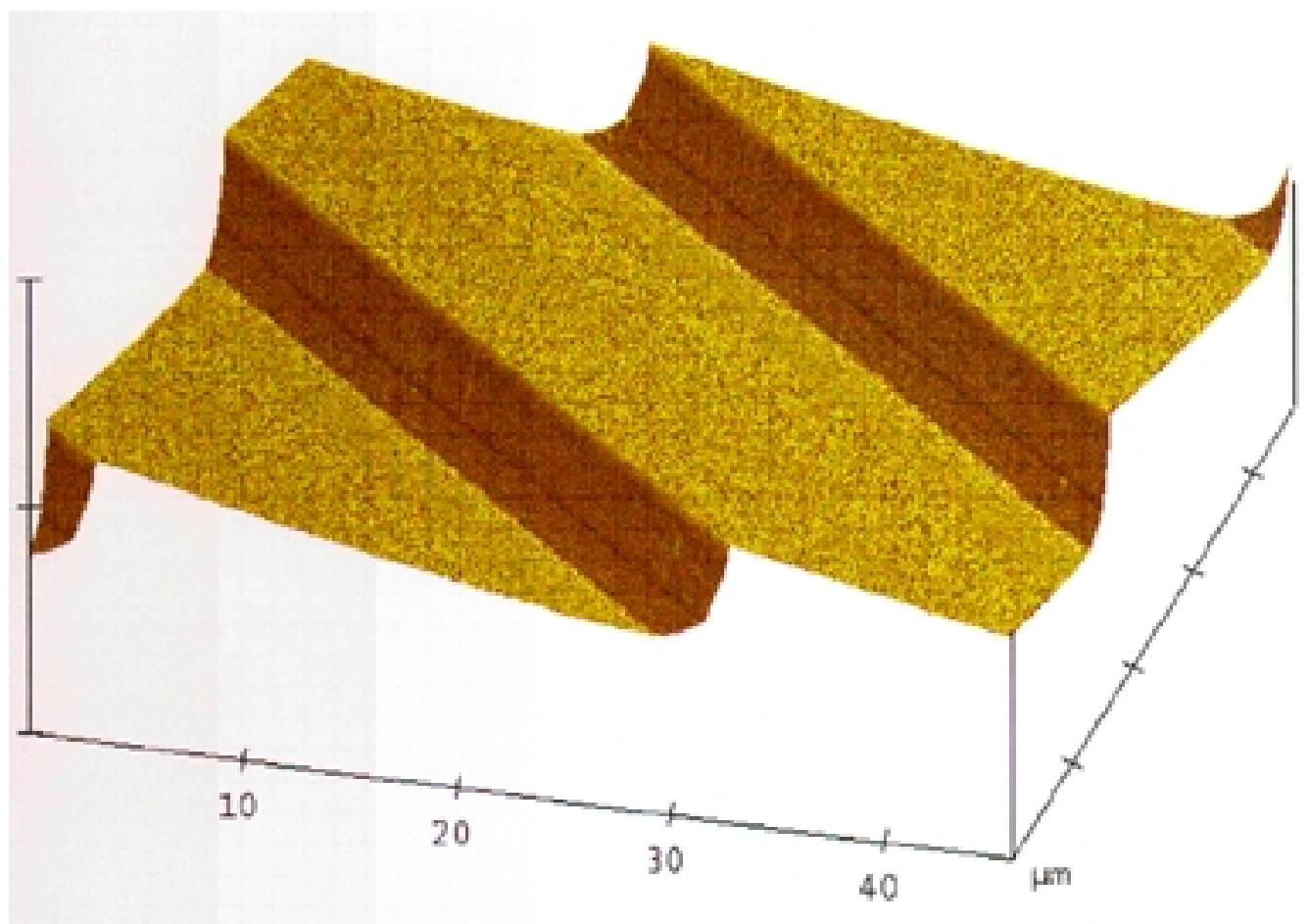

Figure 9 The three-dimensional profile of the machined germanium grating was taken with an atomic force microscope. Vertical scale is 3.0 microns/div. Roughness of blazed surface is $1.1 \mathrm{~nm} \mathrm{rms}$. 